\title{
TESTIMONIO DE LA SUBALTERIDAD SOCIAL EN VENEZUELA
}

Fanny Ramírez de Ramirez* y Edith Pérez Sisto*

\begin{abstract}
RESUMEN: El propósito del presente estudio es develar cómo el testimonio puede ser comprendido como un género literario, diferenciado y diferenciador, entre la novela y los textos procedentes de las ciencias sociales, Asimismo, el testimonio aparece como historia alternativa que posibilita a los sujetos silenciados o excluidos de la "historia oficial" acceder al espacio letrado, salir de la marginalización y generar un discurso contracultural, cuya finalidad central es dar cuenta de la contrahistoria, por una parte, y de la subalteridad política y social, por la otra, en la búsqueda de una reivindicación. El testimonio pretende dar la versión de los acontecimientos ocurridos en el periodo en que ellos se inscriben. El "testimonio oral" se convierte en catarsis o liberación personal, al evidenciar las situaciones extremas padecidas por quien testimonia.
\end{abstract}

Palabras Clave: Subalteridad, Narrativa contracultural, Venezuela.

ABSTRACT: The purpose of this study is to show how the oral testimony can be understood as a literary genre, differentiated and differentiator between the novel and the texts arising from the social science. In the same manner, the testimony appears as an alternative history which makes possible for the silenced and excluded subjects from the "Official History", to access the literary space, and came out from the marginalization and to generate a "counterculture" discourse, which main goal is to asses the "counter-story", on one hand and on the political and social "subalterity", on the other in search of replevying. The testimony pretend to give the account of the facts occurred during the period in which they happened. The "oral testimony" transforms itself into a catharsis or personal liberation while evidentiate the extreme situations suffered by those who give testimony.

KEY WORDS: Subalterity, Narrative couter-culture, Venezuela.

* Universidad Pedagógica Experimental Libertador, Caracas, Venezuela (fannyjotade@yahoo.com).

*Universidad Simón Bolívar, Caracas, Venezuela (esisto@usb.ve). 


\section{ANTECEDENTES}

Las definiciones del arte y la literatura se han basado - por tradiciónen generalizaciones hechas desde la otrora llamada cultura metropolitana. En virtud de ello, rasgos particulares se llevan a esenciales y universales, para desde allí leer lo que pertenece o no a la cultura y a la literatura de nuestro continente. Sin embargo, no podemos obviar que los fenómenos producidos en el interior de aquélla afectan el trabajo de la crítica literaria, y además exigen una lectura problematizadora al interior de la propia disciplina de la literatura. Así, al acercarnos al testimonio tenemos la sensación de abordar la cultura desde la diferencia, quizá porque en América Latina la literatura, en tanto práctica cultural, considera que el testimonio establece una relación problemática entre élites y subalternos; razón que podría explicarnos probablemente, los elementos tipificadores del testimonio, cuya definición ya clásica, es:

[...] una narración [...] contada en primera persona gramatical por un narrador [...] protagonista (o testigo) de su propio relato. Su unidad narrativa suele ser una "vida" o una vivencia particularmente significativa (situación laboral, militancia política, encarcelamiento, etc.). La situación del narrador [...] siempre involucra cierta urgencia o necesidad de comunicación que surge de una experiencia vivencial. ${ }^{1}$

Frente a su posición subalterna el testimoniante como ese "otro", habla para presentar "su verdad"; esa que leemos al comienzo del testimonio de Rigoberta Menchú, de alguna manera paradigma del género: "ya que todo esto lo he aprendido con mi pueblo [...] Mi situación personal engloba toda la realidad de un pueblo". ${ }^{2}$ En el testimonio donde se produce la relación letrado/subalterno, el letrado culto comprometido

\footnotetext{
${ }^{1}$ J. Beverley, Anatomía del testimonio. Del Lazarillo al Sandinismo, Minneápolis, Minnesota, The Prisma Institute, 1987, p. 157.

${ }^{2}$ Rigoberta Menchú Tum, Me llamo Rigoberta Menchú y así me nació la conciencia, ed. e introd. de Elisabeth Burgos-Debray, México, Siglo XXI, 1985, p. 21.
} 
pone en circulación el testimonio desde una perspectiva solidaria y participativa, pero donde están también sus marcas discursivas.

Por eso la motivación por la representación imaginaria del "otro", por los discursos contestatarios, híbridos y desestabilizadores, por las relaciones existentes entre las prácticas discursivas ficcionales y el poder, han producido en las tres últimas décadas del siglo XX, un cambio significativo en los estudios culturales; alteraciones ocasionadas al interior de la cultura que hasta ahora sólo había sido vista, aceptada y propuesta como "cultura letrada". Son cambios que propician la imagen que confronta la figura del autor con la del escritor, en donde había sido preponderante la presencia de sujetos masculinos, fundamentalmente cultos y con expresión escriturada.

Detrás de cada voz testimonial hay un caso, una situación social paradigmática, quizá no en los particulares de la anécdota, pero sí en cuanto a la representación de las condiciones materiales de las que esa voz surge. Por ello, y para que el testimonio tenga valor, es necesario que el mismo vaya de la individualidad hacia la colectividad, desde la afirmación de identidad al reconocimiento de la otredad; de la injusticia a la denuncia, de la vivencia al discurso. Las vivencias y peripecias denunciadas parecen, en consecuencia, ser espejos sobre cuyas superficies se reflejan los innumerables "otros" que permanecen silenciados en la oscuridad. En este sentido el sujeto testimonial está comprometido con su enunciado, surgido de la experiencia vivencial de represión y causante del discurso preferentemente valorativo. Hace hincapié en lo referencial y con esto proporciona un marco de lectura que determina una perspectiva discursiva centrada en ese yo/nosotros y a quien los lectores/ receptores deberán asumir como testigo: actor y juez.

Como veremos, son diversos los motivos del surgimiento de la narrativa de la violencia, en las décadas de los sesenta y setenta, y que aquí abordaremos sólo a partir del testimonio de la subalteridad social. En este trabajo, entonces, analizamos Pito de oro. Voces múltiples del mundo 
de la drogadicción, ${ }^{3}$ Soy un delincuente, ${ }^{4}$ y Biografía con destino. Internado del Consejo Venezolano del Niño. Antesala del delito construcción de un extravio,${ }^{5}$ testimonios en los que las manifestaciones de las voces subalternas se convierten en expresiones que rearticulan, pervierten y subvierten los géneros existentes y propician la aparición de la estética de la periferia cultural. Evidentemente, su consideración adecuada depende de que poseamos los elementos de percepción y apreciación idóneos para analizar este fenómeno discursivo que implica un juicio cultural.

El testimonio podrá ser comprendido "como un género literario, diferenciado y diferenciador, entre la novela y los textos procedentes de las ciencias sociales", ${ }^{6}$ toda vez que surge como una práctica literaria documental en América Latina a partir de los años sesenta, paralelamente a lo que dio en llamarse en el mundo editorial el boom de la literatura latinoamericana. ${ }^{7} \mathrm{El}$ testimonio aparece, así, como historia alternativa que posibilita a los sujetos silenciados o excluidos de la "historia oficial" acceder al espacio letrado, salir de la marginalización y generar un discurso contracultural, cuya finalidad central es dar cuenta de la contrahistoria, por una parte, y de la subalteridad política y social, por la otra, en la búsqueda de una reivindicación (testimonio de disidentes), o una denuncia social (delincuentes). ${ }^{8}$ De esta manera el testimonio, del cual nos interesa precisar el caso venezolano, pretende dar la versión de los acontecimien-

${ }^{3}$ C. Posani, Pito de oro. Voces múltiples del mundo de la drogadicción, Caracas, Fuentes, 1973.

${ }^{4}$ R. Brizuela, Soy un delincuente, Caracas, Fuentes, 1974.

${ }^{5}$ Ramón A. Rodríguez, Biografía con destino. Internado del Consejo Venezolano del Niño. Antesala del delito contrucción de un extravío, Caracas, Fuentes, 1974.

${ }^{6} \mathrm{C}$. Ochando, La memoria en el espejo. Aproximaciones a la escritura testimonial, Barcelona, Anthropos, 1998, p. 25.

${ }^{7}$ Ibid., p. 29.

${ }^{8}$ F. Ramírez de Ramírez, Voces soterradas, ecos del silencio: panorámica del testimonio venezolano (1960-1990), Caracas, Fundación Centro de Estudios Latinoamericanos "Rómulo Gallegos", Dirección de Investigaciones- CDCH-UCV, 1995, p. 26. 
tos ocurridos en el periodo en que ellos se inscriben. Así, el "testimonio oral" se convierte en catarsis o liberación personal, al evidenciar las situaciones extremas padecidas por quien testimonia.

El caso que nos ocupa, se caracteriza por desnudar la descomposición social y familiar, al evidenciar la subalteridad social; sin embargo, debemos señalar, como ya lo han hecho algunos de los teóricos, que sería ingenuo asumir una relación de homología directa entre la historia y el texto. El discurso del testigo no puede ser un reflejo de su experiencia, sino más bien, con palabras de Sklodowska, ${ }^{9}$ su refracción debido a las vicisitudes de la memoria, su intención, su ideología. Aunque la forma testimonial emplea variados recursos en busca de veracidad y autenticidad, el punto de vista de la primera persona (testigo), el juego entre ficción e historia aparecen necesariamente como un problema.

\section{EL TESTIMONIO DE LA VIOLENCIA}

La segunda década del siglo Xx se inicia en Venezuela con la explotación comercial del petróleo a cargo de compañías extranjeras. Ya en 1926 su valor superaba al de todos los productos agrícolas tradicionales (café, cacao), con lo que éste pasa a sustentar toda la economía venezolana y a nuclear la dinámica social del país, como producto de las relaciones que genera su extracción y comercialización.

Su presencia se incorpora de manera nada uniforme a la realidad que transforma cada vez más. A través de una interacción muy compleja se establecen las relaciones básicas entre la actividad económica, la manera como se desenvuelven las fuerzas productivas, la organización de la sociedad y el modo de gobierno que oscila entre logros democratizadores (el sufragio, el derecho de votación para toda la población mayor de 18

${ }^{9}$ Elzbieta Sklodowska, "Miguel Barnet: hacia la poética de la novela testimonial”, $R C L L$, núm. 27, Lima, pp. 139-149. 
años, la elección presidencial y de congresantes) y la contención social de la dictadura perezjimenista, permeada en sus inicios por la corriente de Carlos Delgado Chalbaud, ${ }^{10}$ quien pugnaba por la salida electoral y el mantenimiento parcial del juego político y sindical. Todas estas situaciones inciden en la evolución cultural, el movimiento de la población, las ideologías, los patrones de vida del venezolano, en el periodo que comienza la explotación monoproductora del petróleo hasta 1975, momento de nuestro interés para acercarnos al testimonio.

Esta Venezuela presenta un cambio acelerado que la estructura social no logra armonizar, y trae como consecuencia la agudización de la violencia. ${ }^{11}$ Son años violentos de la insurgencia de la izquierda venezolana, la cual produce un gran número de libros producto de la necesidad de testimoniar los sucesos conformadores de un sueño que a la larga culminó en fracaso.

Los males coyunturales de la democracia generan, en consecuencia, situaciones conflictivas testimoniadas que propician la aparición del testimonio en las voces subalternas y marginadas que ponen en discusión no sólo las "verdades" de la democracia sino los señalamientos desde la Academia, de su condición de "sub-literatura, literatura de masas, narrativa documental" con los cuales peyorativamente se calificó su insur-

${ }^{10}$ Militar, político e ingeniero nació el 20 de enero de 1909 en Caracas. Formó parte de la expedición del Falke, la cual desembarcó en las costas de Cumaná el 11 de agosto de 1929, con la finalidad de destituir del poder a Juan Vicente Gómez. En esta operación fallida murió su padre, por lo que decidió regresar a París. Allí terminó la carrera de ingeniería en la École des Travaux Publics. El 18 de octubre de 1945, participó junto a un grupo de jóvenes oficiales en el golpe de Estado perpetrado contra Isaías Medina Angarita. Así, pasó a formar parte de la Junta Revolucionaria de Gobierno, y asumió el cargo de ministro de Guerra y Marina. El 24 de noviembre de 1948, las fuerzas armadas derrocaron a Gallegos y Chalbaud asumió el poder como presidente de la Junta Militar de Gobierno, acompañado por Pérez Jiménez y Luís Felipe Llovera Páez. Existen muchas teorías y especulaciones sobre su muerte, entre las que se cuentan la que señala a Marcos Pérez Jiménez como el autor intelectual del hecho.

${ }^{11}$ Años en los que el frente bélico de los guerrilleros en las montañas y en las ciudades, tenía su frente cultural en revistas como Cruz del Sur, Sardio y El Techo de la Ballena, entre muchas otras. 
gencia, útil para explicar los nuevos planteamientos que colocan en discusión la relación realidad/literatura.

En los años siguientes, y producto de la situación descrita, se publicará la vasta producción que tematiza la lucha guerrillera, su derrota y desencanto. ${ }^{12}$ También aparece el testimonio de los presos políticos de la democracia, de los presos comunes, de delincuentes, de mujeres. Producción que hasta la década de los años ochenta irá aumentando el corpus de la narrativa testimonial venezolana, conocida por la importante labor de algunos editores y casas editoriales interesados en preservar esta "otra" historia.

El escritor José Vicente Abreu ${ }^{13}$ se hizo responsable de la memoria de estos testimoniadores en la clandestinidad, la cárcel y el exilio, y editó las denuncias contra el perezjimenismo en los "Libros de la resistencia" ${ }^{14} \mathrm{Im}$ posible no destacar la labor de Agustín Blanco Muñoz y Mery Sananes, quienes han reconstruido los procesos políticos de Venezuela en sus últimos 40 años. Ellos recogen el testimonio directo de sus protagonistas, mediante largas entrevistas, resultado de intensos años de investigación, que dejan una importantísima producción plasmada en "Testimonios violentos". ${ }^{15}$

${ }^{12}$ Cfr., los números del Suplemento Cultural de Últimas Noticias del 26 de agosto y el del 9 de septiembre de 1990. Remitimos especialmente a los artículos de Argelia Mellet, Simón Sáez Mérida, Víctor Bravo, Orietta García Golding, Libia Zambrano y Fanny Ramírez. También remitimos al estudio parcial sobre el testimonio venezolano, realizado a partir de los aportes de Phillipa Lejeune, por Orietta García Golding en Letras, núms. 44-45 y 49, y en su tesis doctoral en París (Mimeo). Igualmente es de vital importancia la lectura del libro de Alfredo Chacón, La izquierda cultural venezolana 1958-1968. Ensayo y antología, editada en 1970 por Domingo Fuentes y que ofrece el diálogo entre los acontecimientos históricos que produjeron la guerrilla y condicionaron su fracaso y los hechos que tipifican la discusión ideológica y la actividad cultural en su conjunto, marcadas también por la "indefinición, radicalización y dispersión".

${ }^{13}$ José Vicente Abreu, Se llamaba S.N., Caracas, Centauro, 1964.

${ }^{14}$ Además hay que recordar "Ediciones Bárbara", el "Fondo Editorial Salvador de la Plaza", las editoriales "Ruptura", "Vadell Hermanos", "Publicaciones Selevén" y "Domingo Fuentes".

${ }^{15}$ Estas obras conforman el estudio de "La violencia en la Venezuela reciente: 19581978", Caracas, Universidad Central de Venezuela. Publicaciones que con total regularidad aparecen para consulta de investigadores e interesados en el tema. 


\section{MiRADA A LA ESTÉTICA DE LA PERIFERIA}

Las últimas décadas del siglo Xx produjeron la institucionalización del testimonio latinoamericano y así la historia que había sido silenciada alcanza, como señala Achúgar "el estatuto de prácticas discursivas", ${ }^{16}$ lo que no necesariamente implica que sus límites discursivos sean claros y precisos. En este contexto cobra significación lo que señala Beverley en cuanto a la razón de ser del testimonio y cómo éste escapa a nuestras categorizaciones usuales y, en particular, a la distinción entre lo literario y lo no literario.

De aquí parte nuestro interés por el estudio de la narrativa testimonial venezolana, donde podemos comprobar que nuestras historias de la literatura nacional escasamente consideran este género; más aún, lo han silenciado. Además, las bibliografías sobre la narrativa venezolana (cuento y novela) tampoco señalan su existencia. En definitiva, no se había hecho, hasta la década de los noventa, un arqueo que lo relevara del anonimato y lo organizara como corpus, tarea que asume Fanny Ramírez en sus Ecos del silencio. Panorámica del testimonio venezolano (19601990). Si bien es cierto que las posibilidades de clasificación pueden ser variadas, y todas ellas de algún modo legítimas, en el presente trabajo nos centramos en el testimonio de la subalternidad social. Veamos el corpus, entonces:

En Soy un delincuente ${ }^{17}$ el autor da cuenta de su vida criminal y sus experiencias como ladrón y ex drogadicto, lo que da lugar a un texto que denuncia - a través de la narración de su vida — la situación social del país. Este testimonio devela las consecuencias del sistema social en una de sus víctimas, cuya peripecia personal adquiere carácter representativo. Lo que confiere fuerza al relato y a la denuncia que lleva implícita es su

${ }^{16}$ H. Achúgar, "Historias paralelas/historias ejemplares: la historia y la voz del otro", Revista de crítica literaria latinoamericana, núm. 36n, $2^{\circ}$ semestre, Lima-Perú, Latinoamericana Editores, 1992, pp. 49-72.

${ }^{17}$ Brizuela, op. cit. 
carácter de ser testimonio directo y espontáneo del sujeto que se manifiesta como actor social.

El testimonio se impone como meta la referencialidad directa. Para el escritor, el texto testimonial supone un instrumento de significación de la experiencia vivida y un espacio en donde trascender las propias palabras. Éste se basa en la demostración continua de fidelidad a los referentes, se inserta en el ámbito de lo denominado por Darío Villanueva "realismo genético", es decir, el realismo basado sobre un principio de correspondencia transparente entre los fenómenos externos y el texto literario. ${ }^{18}$ El género testimonio (como forma de registro de la realidad), además, cumple a cabalidad lo que Riffaterre denominó la "ilusión referencial"19 al llenar, a través de lo que hemos denominado "soportes textuales", los vacíos del texto. Los testimonios, nutridos mediante instrumentos de registro de la memoria inmediata, entonces, acortan la distancia entre "signo" y "objeto representado", entre "texto" y "referente", entre "literatura" e "historias", y se erigen como el lugar de la escritura en que, efectivamente, se han podido revisar de nuevo las relaciones entre historia, literatura y vida.

Sin embargo, Soy un delincuente presenta en ocasiones un metafórico escenario a través del relato de la vida del testimoniante en el mundo de la delincuencia. Iniciado desde niño como carterista, finaliza como asesino y asaltante de bancos, donde consigue la muerte a los 21 años al participar en un atraco con la banda ideada por él en la cárcel y organizada desde su última fuga. Cuenta sus peripecias y a la vez cuestiona a esa sociedad que lo formó delincuente. Por ello, seguramente, este testimonio se inicia con la frase: “¿Por qué seré yo así [...]?” Pronto descubrimos que el testimoniante se inició entre los cuatro o cinco años, pidiendo y luego robando. Él nos dice:

${ }^{18}$ Darío Villanueva, Teorías del realismo literario, Madrid, Instituto de España, EspasaCalpe, 1992, pp. 31-70.

${ }^{19}$ Michel Riffaterre, Fictional truth, Baltimore, The Johns Hopkins University Press, 1990 , p. 42. 
En el curso de esta carrera he agarrado muchos castigos. Primero en los retenes del Consejo del Niño, donde cada vez que me fugaba[...] me daban una pela y me encalabozaban nuevamente $[\ldots]$ En esos retenes me castigaron como les dio la gana [...] me hice homosexual, porque allí hay que coger y dejarse coger [...] aprendí a odiar, tanto a la familia como a eso que llaman sociedad $[\ldots] .^{20}$

Desde muy temprano devela el objeto de su odio: la sociedad. Para él, evidentemente, es la sociedad la causante de su desventura, sufrimiento y alienación. Es ampliamente aceptado que una niñez llena de rechazo, abuso y tragedia tiende a producir un adulto infeliz. Freud demostró el impacto de la sociedad y de qué manera influían los patrones dinámicos familiares. El testimoniante nos deja ver ese lado oscuro de lo que él ha vivido:

[...] la mente del castigado es pura maldad y maquiavelismo, siempre pensando en joder a quien pueda, así sea a su propio compañero de castigo [...] el que sea débil tiene que servirle de todo al más fuerte, hasta de mujer, porque en estas celdas meten hasta tres y cinco, y entonces hay uno o dos que se hacen caciques. ${ }^{21}$

El final del testimonio de Brizuela está marcado por una cadena de acontecimientos nefastos, reflejo fiel de su vida: "Es verdad, todo es mierda. Todos somos mierda. ¡Yo también soy mierda! [...]¡Todo es mierda en el mundo en que vivimos! [... ¡ En este mundo drogado que nos encarcela, que nos esclaviza, que nos mata! [....$^{22}$

Él es heredero de las injusticias sociales de su época. A través de estas páginas su voz es un eco resonante de la subalteridad social venezolana.

Eché a rodar mis ojos a lo largo del túnel de cemento. La mayoría de los reclusos estaban sobre el piso gris, recostando sus espaldas a la pared, ha-

\footnotetext{
${ }^{20}$ Brizuela, op. cit., p. 11.

${ }^{21}$ Ibid., p. 13.

${ }^{22}$ Ibid., p. 25.
} 
ciendo lo único que podían. Estaban zarandeando los dados en sus manos, unos; cotorreando vulgaridades [...] y fumando posiblemente todos. Estamos en día martes [...] Sí, era día martes, y allí todos estaban bajo la nube atómica de la ociosidad, envenenándose. Era día martes y me quedé mirando, mirando, para retratar en mi conciencia todas aquellas caracas macilentas [...] En esos momentos yo quería preguntar: ¿Son estos delincuentes? $[\ldots]_{i}$ Soy un delincuente? $[\ldots]_{i}$ Yo no me hice delincuente! ${ }^{23}$

El testimonio de Brizuela es, en consecuencia, una narración en primera persona que presenta una denuncia de la Venezuela arropada por la máscara democrática de un supuesto bienestar social en realidad casi inexistente. Vemos cómo en realidad, es el mismo sistema el responsable del destino de este joven al no brindarle oportunidades para superarse como individuo articulado en una sociedad. En este sentido, cobran singular interés los otros elementos textuales que se integran al presente testimonio, porque en esta subalteridad social, la condición de ejemplar marca en el relato biográfico del relegado, del excluido, lo que no debe ser, lo que esa sociedad no debe "formar".

Pito de oro. Voces múltiples de la drogadicción, por su parte, presenta las voces múltiples del mundo de la drogadicción. ${ }^{24}$ Es un testimonio elaborado por una periodista, cineasta y escritora que trata el problema del consumo de drogas en Venezuela, que a partir de entrevistas constituye este testimonio. Para ello trabaja la autora sobre testimonios directos que impactan por su violencia, sinceridad y franqueza; de allí que se presente al lector como un testimonio que pretende contribuir con una comprensión mejor de las múltiples dimensiones del problema, dadas a conocer desde la simple eficacia de la documentación objetiva, como lo señala su autora en el prólogo.

Pito de oro. Voces múltiples de la drogadicción, nos ofrece una visión de los motivos del surgimiento de la narrativa de la violencia social a partir del testimonio de jóvenes venezolanos, y abre la discusión sobre 
la consistencia de la familia; cuestiona el pilar fundamental de la sociedad: el concepto de familia, el cual, más allá de una definición específica, no ha estado exento de las transformaciones sociales y culturales, mediadas por los procesos sociohistóricos. La fragmentación familiar, responsable en gran medida del incierto destino del niño o adolescente, es la que recibe el impacto de este testimonio para reflejar, en el nivel macro, la descomposición social.

El testimonio de estos jóvenes sumidos en el mundo de la drogadicción es directo; sin embargo, lo que tiene que ser entendido no es la situación inicial del discurso, sino lo que apunta hacia un mundo posible, gracias a la referencia no aparente del testimonio que este texto recoge. La comprensión tiene que ver con captar las proposiciones del mundo abiertas por la referencia del texto; ${ }^{25}$ allí quizá está la razón por la cual el trabajo de Posani va acompañado de fotografías e ilustraciones así como la precisión que hace en la introducción, al apuntar que, en honor a la verdad, se ha tratado de...

No alterar lo dicho por los entrevistados con las groserías, la violencia y las vulgaridades de las imágenes verbales, los errores gramaticales y sintácticos, hasta la pronunciación popular. ${ }^{26}$

Además, su autora señala "la imposibilidad de garantizar su absoluta veracidad, porque debe haberse deslizado cierta cantidad de imaginación y de mentiras", ${ }^{27}$ y produce de esta manera, un diálogo de encuentro con quienes valoran la presencia de la memoria y la imaginación en la elaboración del testimonio, el cual ofrece una presentación de los testimoniantes en primera persona. Así tenemos a Carlos quien "ha venido desesperado a contarte todo lo que durante mucho tiempo se ha callado". ${ }^{28}$

${ }^{25}$ Paul Ricoeur, Teoría de la interpretación. Discurso y excedente de sentido, México,

Universidad Iberoamericana/ Siglo XXI, 1998, p. 100.

${ }^{26}$ Posani, op. cit., p. 14.

${ }^{27}$ Loc. cit.

${ }^{28}$ Ibid., p. 38. 
[...] tú eres su amigo, a quien él contará ese tipo de cosas que sólo le ha confiado a algo que no habla, que tampoco le puede contestar. En la oscuridad de su cuarto le acompaña y, en las noches de calor, humedece de sudor y de lagrimas cuando él da vueltas [...] Vueltas en la cama y le da puños como queriendo que ella pueda gritar y le diga: “¡Basta! ¿Hasta cuando me cuentas tus penas?" Y, en esas noches que son interminables, él se hace la promesa de cerrar su corazón, de no pensar más. De olvidarse de todos, empezando por la abuela que siempre le tira en cara que es hijo natural. De su tía Rosana, a la que siempre le hace favores, esperando de ella una caricia, aunque sea una bofetada. ${ }^{29}$

En el plano psicológico, la figura de la madre es vital. Cuando su orientación y amor están ausentes, el niño anhelará "aunque sea una bofetada" porque ese contacto compensa, psicológicamente, la carencia. Es mejor tener una mala madre a no tenerla. Su ausencia engendrará sujetos alienados socialmente. En el plano simbólico, el país, la nación representan a la madre. Cuando ella falta tendremos un sujeto desarticulado.

Respecto de la joven Aimara de 19 años, conocemos que ha descendido al inframundo de la drogadicción. Su relato dibuja la triste situación de tantos niños abusados tanto física como psicológicamente por quienes debían protegerlos.

Cuando tenía ocho, nueve años, mis padres siempre se iban de viaje a Maracaibo, me dejaban en la casa de mis padrinos. Mi madrina salía por el vecindario, se quedaba mucho tiempo en la calle o él la mandaba a hacer diligencias lejos. Y cuando veníamos de la escuela lo encontrábamos solo, nos daba dulces, caramelos y nos ponía, nos enseñó, a hacer ociosidades [...] Una vez que no quise ir a quedarme [...] con mi padrino, mi papá nos llevó obligadas [...] Hubo una época en que nos dejaron encerradas en el cuarto o salía con mi hermana. Hubo una época en que nos dejaron encerradas en el apartamento. Dejaban la comida y trancaban [...] Yo tenía once, doce años [...] Empezamos a fumar marihuana [...]. ${ }^{30}$

${ }^{29}$ Ibid., pp. 40-41.

${ }^{30}$ Ibid., pp. 50-51. 
En América Latina, los hijos de familias monoparentales tienden a ser más pobres, a abandonar el colegio prematuramente, a estar desempleados y a involucrarse en actividades delictivas con más frecuencia que aquellos niños que en la constitución de su vida familiar, conviven con los dos progenitores. La droga desinhibe y abre las puertas a un mundo fácil de entrar pero difícil de salir. Este testimonio denuncia cómo el mismo padre de la joven induce a que su novio se convierta en jíbaro ${ }^{31}$ y ofrece lo que no dará: "cuando se casen les voy a regalar esto, aquello, lo otro". ${ }^{32}$ Mediante promesas que jamás cumplirá manipula a los dos jóvenes para que satisfagan sus deseos. Tales jóvenes poseen baja autoestima y el caso de Aimara es sólo uno de los innumerables testimonios que presenta Posani, para desmentir las bondades democráticas:

Yo podía ver un muchacho feo, hasta hediondo, que se acercara a mí y le sacaba el cuerpo, pero cuando me metía un tabaco me olvidaba de todo y hacíamos lo que se nos antojara solos o en grupos. ${ }^{33}$

Respecto del testimonio de José, señalemos que se presenta a un joven quien muestra sus deseos, y que probablemente jamás logrará, toda vez que el mismo sistema confabula en su contra. Procedente de una familia de clase media alta, José es también un reflejo fiel de la descomposición social. Veamos:

Tengo dieciséis años y no veo la necesidad de cambiar mi vida $[\ldots]$ mientras fume marihuana $[\ldots]$ no considero que estoy perdiendo mi tiempo [...] Al revés, estoy aprovechando muchísimo mi tiempo. Lo aprovecho en el sentido que tengo el alma divertida, y eso es lo mejor que hay, tengo siempre el ánimo despierto. ${ }^{34}$

Su vida, al igual que la vida de todos esos jóvenes que testimonian, se desperdicia y carece de sentido. Todos quieren "más libertad para ver

\footnotetext{
${ }^{31}$ Modismo venezolano para designar al traficante de drogas.

${ }^{32}$ Ibid., p. 55.

${ }^{33}$ Ibid., p. 53.

${ }^{34}$ Ibid., p. 63.
} 
por mí mismo. El mundo va corriendo más rápido y yo quiero ir a ese ritmo $[\ldots]$ "Es un terreno falso", puede ser, pero eso no me importa, todo es aventura, es descubrir $[\ldots .]^{35}$

De esta manera, el testimonio se ubica en el marco de la tradición latinoamericana del compromiso social y de la narrativa de la violencia, intenta conciliar las formas discursivas sociológicas y antropológicas con las literarias, lo que en el fondo propone es también no sólo una lectura desde una nueva posición con respecto a la literatura, sino sobre todo exige un abordaje interdisciplinario en tanto que fenómeno cultural. Lo que le pasó a El Gato es uno más de los innumerables casos que se repiten en las vidas de estos jóvenes y que nos llega a través de los medios informativos:

Al regreso, cuando ya lo había dejado en su casa, perdió la visibilidad y se metió contra un poste y quedó en el suelo. Le encontraron muchas papeletas en los bolsillos. Él ahora está arriba en el cielo pintando pajaritos y mirándonos a todos aquí, chéveres, chéveres [...] Lo de mi hermano no me afectó en nada. Al momento me fui por ahí, chévere paseando con mi material y vendiendo mezcal [...] y fuera [...] Los efectos del mezcal son parecidos al LSD, pero más suaves $[\ldots] .^{36}$

Como vemos, desde este enunciado el testimoniante habla de todo porque desea, pero no sabe ni puede alcanzar aquello que anhela. De su testimonio inferimos que su vida carece de orientación y rumbo. Se presenta como un sujeto desarticulado socialmente. Sus palabras y acciones apuntan claramente hacia su autodestrucción ya sea por la vía de la droga o por el impacto de una bala perdida en alguna estrecha calle de algún barrio venezolano. ${ }^{37}$

Sí claro, muchas veces quisiera no haber salido de mi casa. Entre mis compañeros todo es confusión, angustia [...] Sí claro, soledad. Aunque muchos

${ }^{35}$ Ibid., p. 66.

${ }^{36}$ Ibid., p. 71.

${ }^{37}$ Por "barrio venezolano" se designa a una barriada donde hay muchas deficiencias en cuanto a servicios públicos, ausencia de planificación urbana y la preeminencia de los antivalores. 
no lo dicen, nos sentimos muy solos. Interiormente, hay una sensación de angustia, de encontrar algo, no se qué buscamos, no sé [...] Ese constante buscar y no encontrar nada nos coloca en una situación desesperante. ${ }^{38}$

Las voces que hacen eco sus conflictos, temores, frustraciones y abandono, en estos textos documentales, como Biografía con destino. Internado del Consejo Venezolano del Niño. Antesala del delito construcción de un extravio, ${ }^{39}$ tienen como característica el relato biográfico. Este testimonio refiere la historia de un hombre a quien su condición de niño abandonado lo lleva a ser criado en los albergues construidos para internar a tales niños. Este discurso de la subalteridad social utiliza palabras convencionales, dibuja formas propias de las colectividades cuyos miembros no quieren ser comprendidos por los extraños, como, por ejemplo, sucede en las prisiones.

El joven relata los padecimientos y torturas a las que fue sometido: golpizas con cucharones, ejercicios militares hasta el desmayo (rampar, salto de la gallina y del ganso); también cuenta la manera en cómo su madre lo entregaba después de sus huidas y sus aprendizajes e intentos de suicidio a las casas de readaptación, entonces denominados retenes de menores (menciona el de Los Teques, el de Los Chorros, el de la Isla de Tacarigua). Hace relación de las torturas que padeció en todos los lugares en los cuales fue recluido, así como de las vejaciones y torturas sufridas, y las prácticas homosexuales de los superiores, incluido un sacerdote. Señala dos obsesiones: el suicidio y la fuga y los intentos fallidos y logrados al respecto (la hoz, la naftalina, la huida nadando por la laguna a pesar de su debilidad física). Cuenta cómo allí cumple la mayoría de edad y el Consejo Venezolano del Niño lo envía a la calle, donde trabaja y compra para su mamá un apartamento del Banco Obrero en un intento de autorregeneración, pero por las enseñanzas recibidas a los 7 meses cae preso y lo envían a la cárcel modelo.

\footnotetext{
${ }^{38}$ Ibid., p. 128.

${ }^{39}$ Rodríguez, op. cit.
} 
Cuenta en su relato autobiográfico/picaresco, cómo su madre logra su traslado a Bárbula ${ }^{40}$ sosteniendo su desequilibrio mental, de donde se escapa, se casa y luego de trabajar es traicionado por su mujer con su hermano, ante lo cual no toma represalias, explica, por respeto a su hija. Luego pasa por los aprendizajes del contrabando hasta aparecer en la prensa como asaltante de banco y asesino aun cuando nunca lo fue, hecho que en este relato autobiográfico lo lleva, según propia confesión a armarse, una vez que se siente enemigo de la sociedad. Luego se hace taxista y vendedor de perfumes; es buscado por la DIGEPOL ${ }^{41}$ al creerlo comunista pero posteriormente lo dejan en libertad.

El relato señala al final del "testimonio de una frustración", como califica su libro, que lo deja escrito ante la convicción de que será útil -y aquí su ejemplaridad - para quien desee hacer de cualquier niño del cerro, la quebrada o la barranca, en virtud de su solidaridad, un hombre, absolutamente hombre, porque él logra salir absuelto y desea estar al lado de sus hijos a quienes confiesa amar, pero en cuya vida no quiere ver jamás una parte de la historia por él vivida.

Cierra el texto con una reflexión según la cual aborda el plano real de una Ciudad Dorada que se perdió en la bruma creada alrededor de su propio centro - la infancia - por hombres equivocados en el quehacer vital ${ }^{42}$ y concluye con un "Vocabulario de modismos carcelarios" y varias reseñas de informaciones de prensa del incendio en el albergue de Zabaneta Estado Zulia, donde se amotinan, incendian, mueren y escapan muchos de los jóvenes, situación además reafirmada con las reseñas de prensa insertadas para dar fe de la verdad testimoniada en un juego intertextual articulado a la verdad de los hechos noticiosos que la sustentan. Ella junto a un discurso oficial que pretende atender y solucionar males sociales creados aunque no articulados a las fallas del sistema democrático, con lo cual el autor de este testimonio consigue interpelar al

\footnotetext{
${ }^{40}$ Centro psiquiátrico venezolano.

${ }^{41}$ Dirección General de Inteligencia.

${ }^{42}$ Rodríguez, op. cit., p. 14.
} 
lector desde la función denunciatoria y ejemplarizante del mismo, para cuestionar a una sociedad contra la cual la subalteridad social establece su desafío.

\section{AlgunAS REFLEXIONES FINALES}

Los motivos del surgimiento de la narrativa de la violencia, en las décadas de los años sesenta y setenta, a partir del testimonio de la subalteridad social en las obras seleccionadas, otorga la palabra a aquellos protagonistas reales, de carne y hueso, cuyas voces no encuentran eco en un sistema que los devora, en un momento y un lugar concretos, de la historia y la literatura. La vida reflejada en la literatura testimonial no pertenece al ámbito privado e íntimo, sino al social. Es representativa de un grupo social marginado y transformadora de una situación de injusticia.

El uso del monólogo orienta al lector hacia una versión panorámica de los acontecimientos narrados. Los testimonios son tan variados como la procedencia o clase social de los testimoniantes. En su mayoría jóvenes insatisfechos que buscan gratificación y apoyo fuera de los confines de la familia. Y es que el común denominador de estos testimonios apunta hacia la descomposición familiar, de su incapacidad de brindar al adolescente un contexto seguro para que pueda alcanzar su máximo potencial como seres humanos dignos. Esto a la vez es reflejo de la descomposición social en la cual está inserta la familia. Los relatos nos hablan de violaciones, abandono, maltrato físico y psicológico.

Las emociones asociadas al trauma no se expresan de manera directa, simplemente se evaporan. Más bien, se visualizan a través de la conducta de forma vaga, imprecisa. El trauma se deriva del conflicto creado entre la propia experiencia interior y la irrupción de un agente exterior que genera un punto de inflexión en ese desarrollo psicológico. De acuerdo con Freud, tenemos una tendencia a negar o resistir estas motivaciones de su percepción consciente, de manera que sólo son observables de forma disfrazada. 
Esta narrativa testimonial venezolana nos muestra la otra cara de la "historia oficial", la contrahistoria; así como la tematización de otras formas de subalteridad, ya sea desde la perspectiva de reinvidicación de esas voces, o sólo desde la denuncia. Esos sujetos sociales, poseedores de una carga contestataria, se hicieron escuchar desde el espacio subalterno en el que habían permanecido oprimidos y dependientes, dejaron testimonio escrito de esa exclusión que a la vez se convirtió en inserción. Este testimonio surgió como historia alternativa que posibilitaba $-\mathrm{y}$ continúa posibilitando- a los sujetos silenciados o excluidos de la "historia oficial" acceder al espacio letrado, salir de la marginalización y generar un discurso contracultural que curiosamente sigue teniendo vigencia en la Venezuela del siglo XXI.

Debemos, por eso, tener presente que el testimonio es un género de "urgencia", y la narración en primera persona se da para contar los padecimientos de un colectivo expresado por esa voz que no se deja silenciar. Esto se hace evidente en la narrativa testimonial venezolana. Ella escribe la otra cara de la "historia oficial", la contrahistoria. Así posee una clara función ejemplarizante; es decir, útil y moralizante, acompañada de la función denunciatoria.

\section{BIBLIOGRAFÍA}

Abreu, José Vicente, Se llamaba S.N., Caracas, Centauro, 1964, pp. 36. ACHÚGAR, HugO, "Historias paralelas/historias ejemplares: la historia y la voz del otro", Revista de crítica literaria latinoamericana, núm. 36, $2^{\circ}$ Semestre, Latinoamericana Editores, Lima-Perú, 1992, pp. 4972 .

Beverley, John, Anatomía del testimonio. Del Lazarillo al Sandinismo,

Minneápolis, Minnesota, The Prisma Institute, 1987, pp. 153-168. BRIZUELA, RAMÓN, Soy un delincuente, otras verdades de la democracia, Caracas, Fuentes, 1974, pp. 2-60. 
Freud Sigmund, Obras completas III, Buenos Aires, Amorrortu, 1994. Menchú Tum, RigobertA, Me llamo Rigoberta Menchú y así me nació la conciencia, ed. e introd. de Elisabeth Burgos-Debray, México, Siglo XXI, 1985, p. 21.

Ochando, C., La Memoria en el espejo. Aproximaciones a la escritura testimonial, Barcelona, Anthropos, 1998, 48 pp.

Posani, Clara, Pito de oro. Voces múltiples del mundo de la drogadicción, Caracas, Fuentes, 1976, pp. 4-50.

RAMíreZ DE RAMíREZ, FANNY, Voces soterradas, ecos del silencio: panorámica del testimonio venezolano (1960-1990), Caracas, Fundación Centro de Estudios Latinoamericanos "Rómulo Gallegos", Dirección de Investigaciones, 1995, pp. 2-50.

Ricoeur, Paul, Teoría de la Interpretación. Discurso y excedente de sentido, México, Universidad Iberoamericana/Siglo XXI, 1998, 100 pp.

RifFATERre, Michel, Fictional truth, Baltimore, The Johns Hopkins Univerty Press, 1990, 42 pp.

Rodríguez, RAmón, Biografía con destino. Internado del Consejo Venezolano del Niño. Antesala del delito, Caracas, Fuentes, 1974, pp. $3-49$.

Sklodowska, ElzBIETA, Testimonio hispanoamericano. Historia, teoría, poética, Nueva York, Peter Lang Publishing, Inc, 1991, 219 pp.

VillanueVa, DARÍo, Teorías del realismo literario, Madrid, Instituto de España, Espasa-Calpe, 1992, pp. 31-70. 